Article

\title{
Delineating Urban Fringe Area by Land Cover Information Entropy-An Empirical Study of Guangzhou-Foshan Metropolitan Area, China
}

\author{
Junyi Huang ${ }^{1,2, *}$, Qiming Zhou ${ }^{1}$ and Zhifeng $\mathrm{Wu}^{2}$ \\ 1 Department of Geography and Centre for Geo-computation Studies, Hong Kong Baptist University, \\ Kowloon Tong, Kowloon, Hong Kong; qiming@hkbu.edu.hk \\ 2 School of Geographical Sciences, Guangzhou University, Guangzhou 510006, China; gzuwzf@163.com \\ * Correspondence: jrhuang@life.hkbu.edu.hk; Tel.: +852-3411-5986
}

Academic Editors: Zhilin Li and Wolfgang Kainz

Received: 15 February 2016; Accepted: 3 May 2016; Published: 6 May 2016

\begin{abstract}
Rapid urbanization has caused many environmental problems, such as the heat island effect, intensifying air pollution, pollution from runoff, loss of wildlife habitat, etc. Accurate evaluations of these problems demand an accurate delineation of the spatial extent of the urban fringe. Conceptual and analytical ambiguity of the urban fringe and a general lack of consensus among researchers have made its measurement very difficult. This study reports a compound and reliable method to delineate the urban fringe area using a case study. Based on the 'fringe effect' theory in landscape ecology, the existing land cover information entropy model for defining the urban fringe is renewed by incorporating scale theory, cartography and urban geography theory. Results show that the urban fringe area of Guangzhou and Foshan metropolitan area covers an area of $2031 \mathrm{~km}^{2}$, and it occupies over $31 \%$ of the total study area. Result evaluation by industry structure data shows satisfactory correspondence with different land cover types. This paper reports the method and outcome of an attempt to provide an objective, repeatable and generally applicable method for mapping its spatial extent from remote sensing imageries, and could be beneficial to relevant urban studies and urban fringe management projects.
\end{abstract}

Keywords: urban fringe area; remote sensing; information entropy; Guangzhou-Foshan metropolitan area

\section{Introduction}

Increasing population and urbanization result in the most complex process of land use and land cover changes from the local to global scale. The urban fringe is a transition zone from urban to rural areas. It is usually characterized by a strong mixture of different landscapes. Its land cover is also the most sensitive, dynamic and swiftly changing under rapid urbanization processes. The metropolitan area, which develops with suburbanization, forms an extension of, and later integrates with the existing urban area. In the past three decades, rapid economic and population growth in China have facilitated the formation of regional and international metropolitan areas (e.g., Yangtze River Delta and Pearl River Delta Regions). The landscape, particularly in former rural areas, has changed dramatically, characterized by mosaics of built-up areas (e.g., residence, factory or infrastructure) and agricultural land-use types (e.g., farmland, orchard or fish-pond) [1].

Determining the urban morphology is fundamental for sustainable urban development studies [2], and it is also beneficial to delineate the area of interest when answering a wide range of environmental research questions related to the role of urbanization in climate, biogeochemistry and hydrological cycles [3]. Nevertheless, the importance of identifying the fringe region is generally overlooked [4]. 
It is therefore critical to have an objective and consistent method to delineate the urban fringe area, to assist in managing and mitigating the potential adverse consequences of this landscape alteration.

Delineating the urban fringe area remains a subjective process. In the early era, Hezber Louis [5] proposed the concept of the "Urban fringe area" ("Stadtrand zonen") in 1936. Several attempts were reported in which a variety of socio-economical parameters and metrics were adopted [6-10]. Most of the above efforts relied mainly on census and survey data. While these data provide most of the knowledge on the socio-economic environment, they do not allow for gradients of values, and suffer from spatial mismatch between the working places and residences for most people [11]. The idea of a continuum suggests that urban and rural areas are, in fact, the ends of a continuum, rather than representing a dichotomy [11].

Remote sensing offers the possibility of combining physical and morphological data with demographic and socio-economic data in one application [12]. Land cover change information represents the interface between biophysical conditions and anthropogenic influences through time [13]. Numerous studies on this topic using remote sensing techniques have been reported. Zhang et al. [14] specified a threshold of land cover information entropy (also known as Shannon Diversity Index) as the urban fringe. Wilson et al. [15] also developed an urban growth model that could be utilized to delineate the urban fringe area. Angel et al. [16] proposed a criterion of the percentage of built-up pixels to delineate the urban fringe. Meaningful results were obtained from these models. However, the analysis scale and delineation threshold are determined arbitrarily. It is unsurprising, therefore, that the level of reproducibility among different mappers and for different regions is limited.

As a fundamental issue in geo-sciences, the effects of scale are well recognized as the basic property and "one of the most fundamental aspects of any research" [17,18]. This explicit emphasis on spatial heterogeneity necessitates the consideration of the effect of scale in defining the spatial extent urban fringe $[19,20]$.

To summarize, when trying to delineate the urban fringe area, the following problems must be addressed [11]:

(a) What variable(s) should be used as an indicator of how urban or what rural it is?

(b) On what scale should it be analyzed and calculated?

(c) How will the indicating variable(s) be measured?

Therefore, this study aims to develop a methodology for identifying the spatial extent of the urban fringe. The land cover information entropy value, obtained from remote sensing imagery, will be used as the primary indicator. An appropriate scale for analysis will be identified for better efficiency. Values will be analyzed from various directions to reflect the urban sprawl morphology. A map illustrating the spatial extent of urban core, urban fringe and rural area of the study area will be presented.

\section{Study Area and Data}

Guangzhou and Foshan are located in Guangdong Province in southern China (Figure 1). They are the first and third largest cities of the province in terms of Gross Domestic Product (GDP), with a highly integrated transportation system, complementary industrial structure, and similar cultural tradition. These conditions have led to the development of Guangzhou-Foshan metropolitan area. Gaoming District of Foshan is excluded from the study area due to its isolated location.

One scene of predominantly cloud-free Landsat Thematic Mapper (TM) image (December, 2008) was acquired with a resolution of 30 meters. Image pre-processing techniques such as image geo-referencing and subset, atmospheric correction and radiometric correction were performed. The maximum likelihood classifier was chosen to classify the land cover. Based on the land resources and socio-economic condition of Guangzhou and Foshan, land cover was classified into six categories: Built-up area (urban residential land and industry land), Orchard, Farmland, Forest, Dike/pond, Water body and Newly developed land. The training polygons were digitized on-screen based on the landscape knowledge acquired during fieldwork and distributed throughout the study area. 
The classified images were assessed for accuracy based on a random selection of 200 reference pixels, which were compared against ground truth data, which can be obtained from aerial photos, published land use maps or field visits. The overall classification accuracy is $88.2 \%$, the Kappa coefficient is 0.83 . Among these types of land use, built-up area had highest classification accuracy; farmland had lowest classification accuracy.

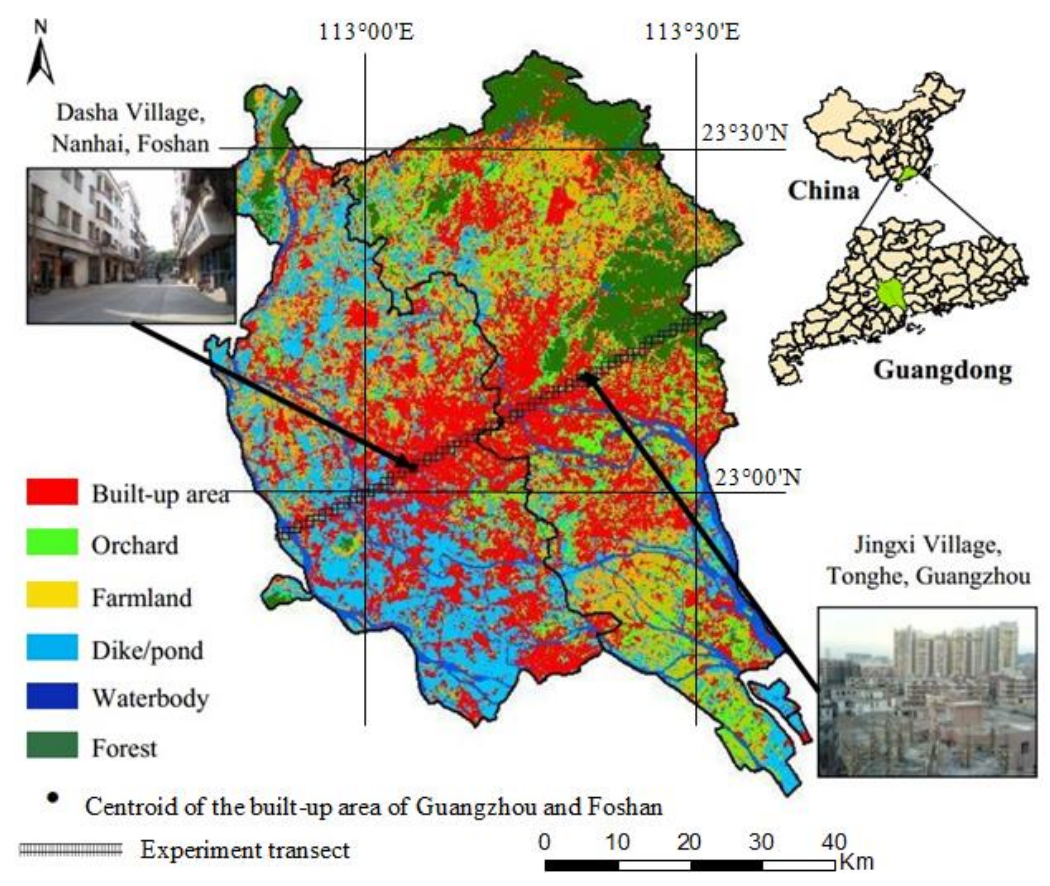

Figure 1. The study area and land cover map of the study area in 2008 and the sample transect crossing two centroids of the built-up area of Guangzhou and Foshan.

\section{Methodology}

\section{1. 'Fringe Effect' and Land Cover Information Entropy Model}

The creation of an urban-rural gradient requires knowledge of how urban or rural a place is. An ecotone, a transition area between two biomes or different patches of the landscape [21], presents a tendency of increased biodiversity referred to as the 'fringe effect' since it provides greater spatial and temporal variation in resources [22]. The Shannon Diversity Index (SHDI) is often adopted to estimate the level of biodiversity in a certain biome [23], and this index, also known as the information entropy value, is perhaps the most widely used and reliable technique to measure the extent of urban sprawl with the integration of remote sensing and Geographic Information System (GIS) [24]. It is introduced to measure the land cover disorder degree reflected by remote sensing images.

$$
H=-\sum_{i=1}^{\mathrm{n}} P_{i} \ln P_{i}
$$

In Equation (1): $H$ is the diversity index (information entropy value). $P_{i}$ is the proportion of area covered by land cover class $i$. It quantifies the diversity of land cover type based on two components: the number of different land cover types (richness) and the proportional area distribution among land cover types (evenness). As a general rule, the index $(H)$ rises when the number of land cover classes increases and when the proportion of small classes approaches that of large classes in a given unit of measurement. One of the basic assumptions of this study is that higher diversity index (information entropy value), which corresponds to a diversified land cover status, indicates urban fringe, while lower diversity index (information entropy value) indicates urban core or rural area. 


\subsection{Optimal Scale Selection}

In this study, selecting an optimal scale for calculating and analyzing the land cover information entropy is essential in order to better preserve the pattern and reduce data redundancy. Cells in a series of resolution $\left(240 \mathrm{~m}\left(S_{1}\right), 480 \mathrm{~m}\left(S_{2}\right), 960 \mathrm{~m}\left(S_{3}\right), 1920 \mathrm{~m}\left(S_{4}\right)\right.$ and $\left.3840 \mathrm{~m}\left(S_{5}\right)\right)$ are created to calculate the diversity index, with reference to some previous similar studies [14-16]. Selection of a typical transect is the very important first step. A transect passing two centroids of the Guangzhou and Foshan built-up area (Guangzhou: $113^{\circ} 08^{\prime} \mathrm{E}, 23^{\circ} 07^{\prime} \mathrm{N}$, Foshan: $113^{\circ} 04^{\prime} \mathrm{E}, 23^{\circ} 02^{\prime} \mathrm{N}$ ) is created (Figure 1 ). Because it crosses two urban areas (Guangzhou and Foshan), as well as a wide range of land cover types in the study area, its spatial heterogeneity is most representative.

The optimal scale is determined from the following two principles: Value stability and spatial heterogeneity preservation. (I) Value stability: Calculate the average information entropy values (referred to as variable $x$ ) of the cells on individual transects, followed by a second-degree polynomial fit for all $x$ (Equation (2)). When $f^{\prime}(x)=0$, its corresponding stationary point of the curve is $S_{0}\left(x_{0}, y_{0}\right)$.

$$
\begin{aligned}
& f(x)=\mathrm{a} x_{i}^{2}+\mathrm{b} x_{i}+\mathrm{c}(i=1,2,3,4,5) \\
& S_{a}=\left\{S_{i}|\min | S_{i}-S_{0} \mid, i=1,2,3,4,5\right\}
\end{aligned}
$$

In Equation (3), variable $S_{i}$ is scale (cell size), which has five possible values: $S_{1}, S_{2}, S_{3}, S_{4}$ and $S_{5}$. Identify the $S_{i}$ as the most stable scale $S_{a}$ that is the most adjacent to stationary point $S_{0}$ (Equation (3)).

(II) Spatial heterogeneity preservation: Due to a significant heterogeneity pattern along the sample transect (crossing both urban core areas of Guangzhou and Foshan), the ideal entropy value curve should present a 'low (rural area, southwest) $\rightarrow$ high (urban fringe) $\rightarrow$ low (urban core of Foshan) $\rightarrow$ high (urban fringe) $\rightarrow$ low (urban core of Guangzhou) $\rightarrow$ urban fringe $\rightarrow$ rural area (northeast) pattern. The patterns of all five curves will then be visually inspected. The optimal scale will be selected based on the best fitting accuracy, maximum spatial heterogeneity preservation and minimum data redundancy, where tradeoffs exist.

The following analyses will be based on the optimal scale obtained from (I) and (II) above.

\subsection{Analysis of Land Cover Information Entropy}

Sixth-degree polynomial fittings are conducted for the entropy values $(z)$ for cells in different rows (latitude direction) and columns (longitude direction) (Equation (4)). Subsequently, inflection points (where second order derivative equals to zero) for individual rows and columns are obtained. As shown in Figure 2 and Equation (5), the convex part(s) between two inflection points is the high entropy value part, and the remaining concave part(s) between two inflection points is the low entropy value part, representing the urban fringe area and core area, respectively.

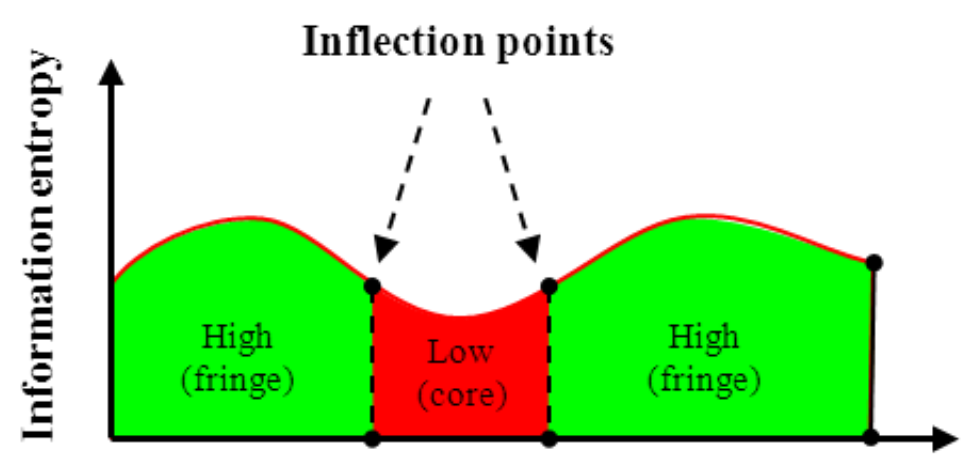

Figure 2. Inflection point recognition for information entropy analysis.

Third-degree polynomial fittings are also conducted for the entropy value $(z)$ for cells in $60 \mathrm{~km}$-long transects in 16 directions (N, NNE, NE, ENE, E, ESE, SE, SSE, S, SSW, SW, WSW, W, 
WNW, NW and NNW). A polar graph (radius direction) is created with the fixed point as the centroid of the entire built-up area.

$$
\begin{gathered}
g(z)=\mathrm{a} z_{i}^{3}+\mathrm{b} z_{i}^{2}+\mathrm{c} z_{i}+\mathrm{d} \\
g^{\prime \prime}(z)\left\{\begin{array}{l}
<0 \text { relatively high value area } \\
>0 \text { relatively low value area }
\end{array}\right.
\end{gathered}
$$

\subsection{Integration of Recognition Results}

The latitude direction (A) and longitude direction (B) analysis methods mentioned above can only analyze the land use information entropy values in their particular direction. Complementarily, the radius direction $(\mathrm{C})$ method mentioned above better simulates the urban sprawl process. In this study, in order to produce a close-boundary result for the urban core, urban fringe and rural area, we will integrate the above three analysis methods and produce a high entropy value area as:

$$
(\mathrm{A} \cup \mathrm{B}) \cap \mathrm{C}
$$

The result of this set is the final delineation result of the urban fringe area of the metropolitan area.

\section{Results}

\subsection{Optimal Scale for Calculating and Analysing Information Entropy}

\subsubsection{Value Variation on Different Scales}

Figure 3 shows the response of the average entropy value to different scales. From scale $240 \mathrm{~m}$ to $1920 \mathrm{~m}$, the average value increases as the cell size becomes longer, while from $1920 \mathrm{~m}$ to $3840 \mathrm{~m}$, it starts to decrease. According to Equations (2) and (3), $S_{3}(960 \mathrm{~m})$ is the scale that is most adjacent to stationary point $S_{0}$, which was obtained when $f^{\prime}(x)=0$. Therefore, $960 \mathrm{~m}$ was chosen as the optimal scale to calculate the information entropy. The change of entropy value is most stable at this stationary point.

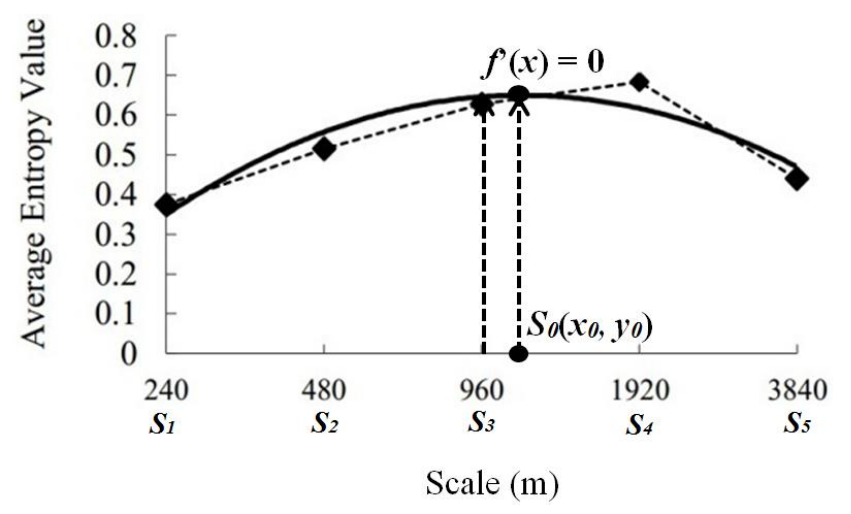

Figure 3. The response of the average entropy value to different scales.

\subsubsection{Spatial Heterogeneity on Different Scales}

Figure 4 presents the pattern of information entropy value at different scales. The patterns are strongly influenced by the scale variation. At the scales from $1920 \mathrm{~m}$ and $3840 \mathrm{~m}$, most land cover diversity information is lost due to over-generalization. At the scale of $240 \mathrm{~m}, 480 \mathrm{~m}$ and $960 \mathrm{~m}$, the spatial heterogeneity patterns can be distinguishable. However, data redundancy increases as the cell size gets smaller. Therefore, $960 \mathrm{~m}$ was chosen as the optimal scale due to the spatial heterogeneity preservation and minimum data redundancy. This result agrees with the analysis in Section 4.1.1. 

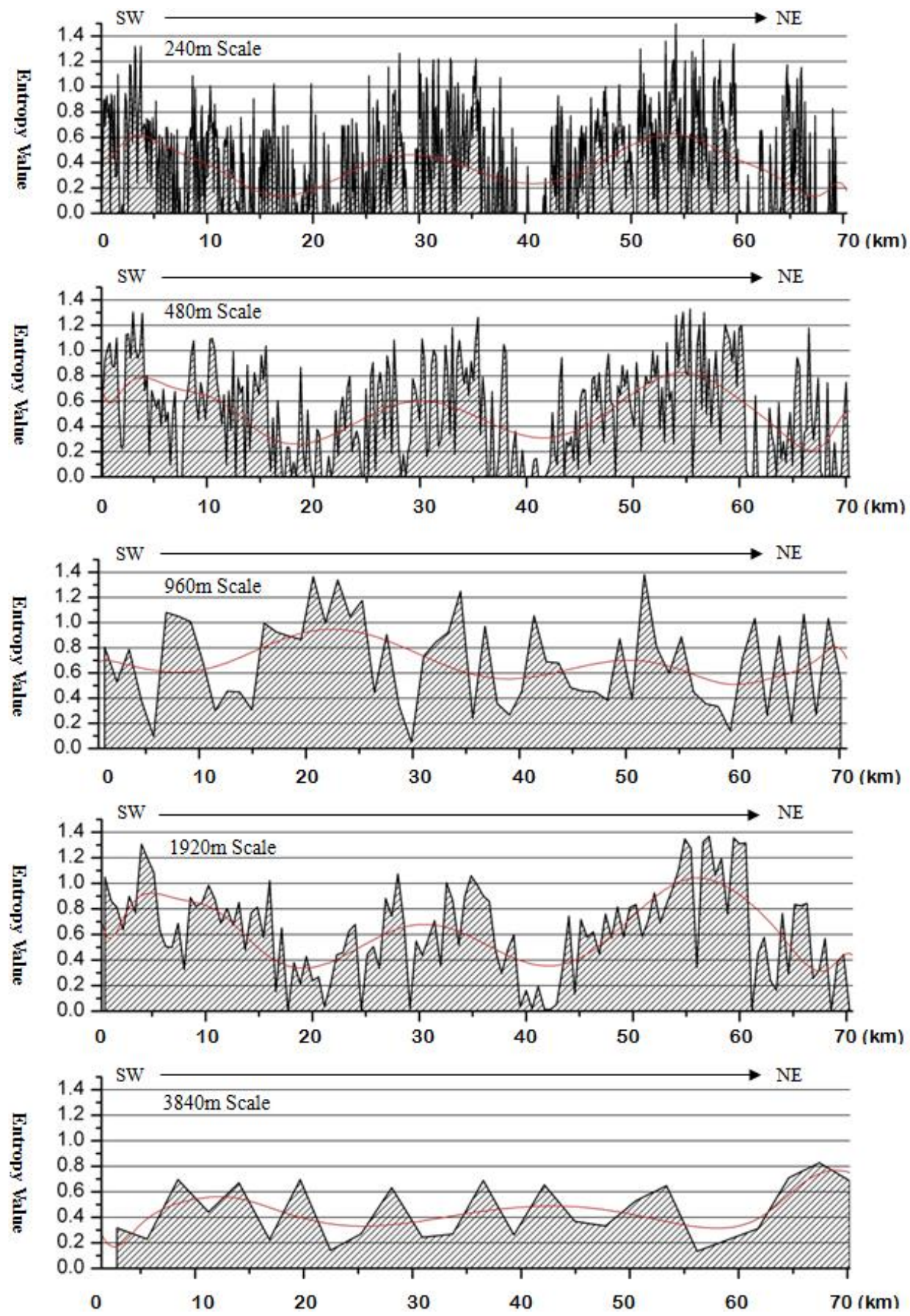

Figure 4. The information entropy value variation at different scales $(240 \mathrm{~m}, 480 \mathrm{~m}, 960 \mathrm{~m}, 1920 \mathrm{~m}$, $3840 \mathrm{~m})$.

\subsection{Quantitative Recognition of the Information Entropy Image}

\subsubsection{Entropy Value Overall Analysis}

On the optimal scale ( $960 \mathrm{~m}$ ) obtained above, a total of 7081 cells covering the whole study area is created, followed by the calculation of land cover information entropy values of each cell. There is no apparent concentration of the "higher value area", since the overall urbanization level in the study area is high while different land cover types exist. It also shows a satisfactory indication of the urban fringe area based on preliminary visual assessment. Thus, SHDI can be assumed as a feasible indicator of the urban fringe in the study area. 


\subsubsection{Latitude and Longitude Direction}

As in Figure 5a (latitude direction) and Figure $5 b$ (longitude direction), the area covered by green and yellow stripes is the relatively high entropy value area, and the remaining area is the relatively low entropy value area. The green stripes cover an area of $3296 \mathrm{~km}^{2}$, occupying over $49 \%$ of the total study area. The yellow stripes cover an area of $3510 \mathrm{~km}^{2}$, occupying $52 \%$ of the total study area. This recognition method has its advantage in clarifying the urban area and rural area as a relatively low value part, and the urban fringe area, covered by green stripes (yellow stripes) as a relatively high value part in the latitude direction (longitude direction). Sample site verification has also been conducted in the six transects, in an effort to evaluate the recognition accuracy.

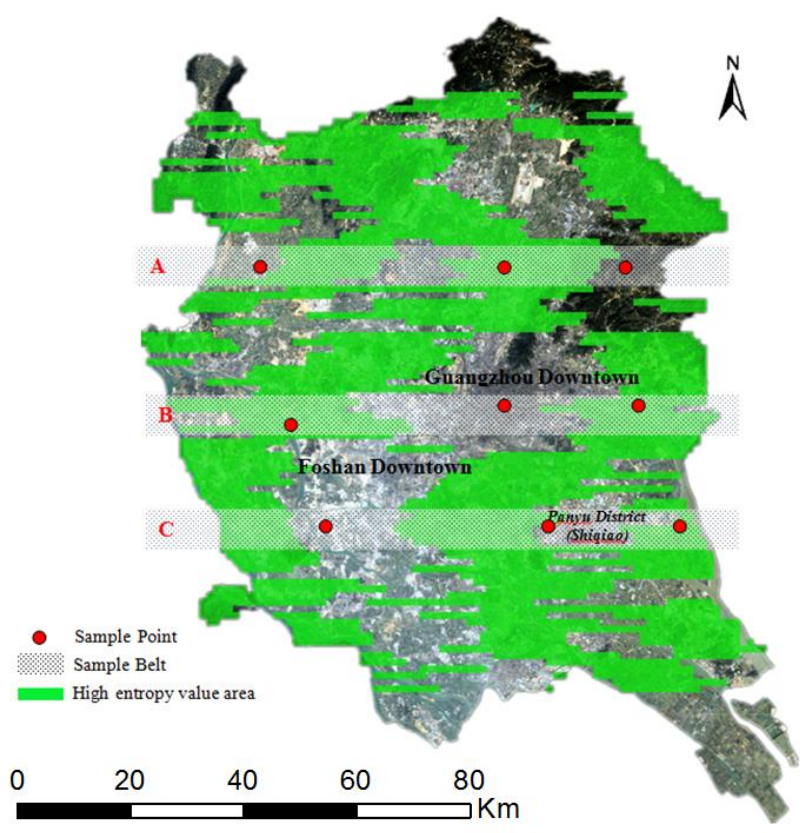

(a)

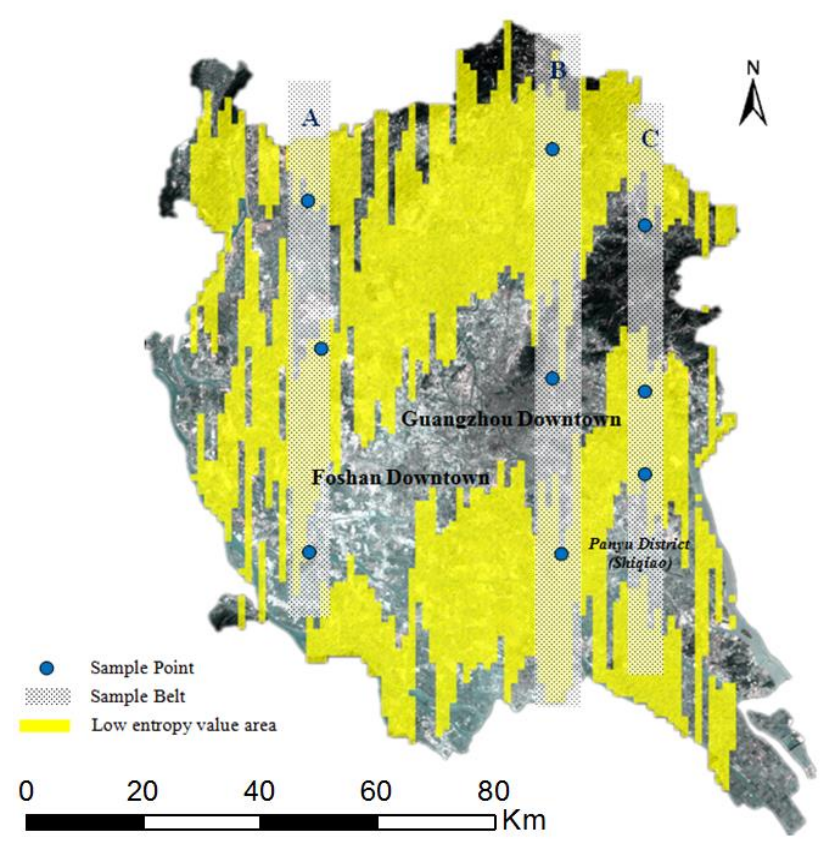

(b)

Figure 5. Cont. 


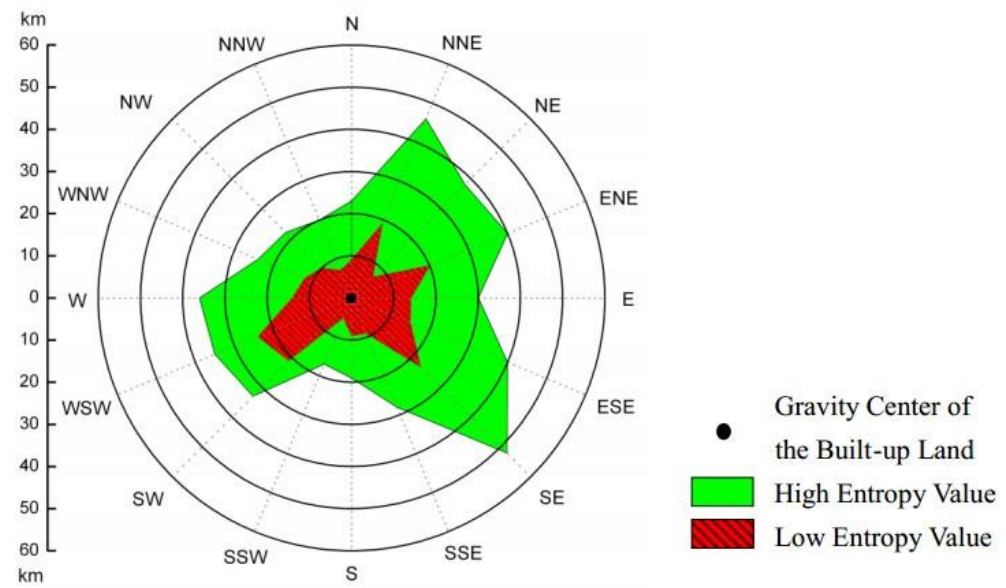

(c)

Figure 5. Latitude direction (a); longitude direction (b) and radius direction (c) recognition result.

\subsubsection{Radius Direction}

As in Figure $5 \mathrm{c}$, the polar graph represents an area of a $60 \mathrm{~km}$ radius, which radiates from the centroid of the build-up land of the study area. The green part is the high information entropy value area while the red part is low. As a complement of the latitude and longitude direction recognition, it simulates the urban sprawl and delivers a result with a complete boundary of urban fringe. However, it has over generalized the urban morphology as there are several sub-cores situated in the surrounding metropolitan area.

\subsection{The Final Mapping Result of the Urban Fringe Area and Analysis}

Figure 6 shows the final urban fringe area delineation result, integrating three different entropy mapping techniques as described above. The result is generally consistent with the local situation. The urban core area of Guangzhou and Foshan metropolitan areas covers an area of $733 \mathrm{~km}^{2}$, and it occupies over $11 \%$ of the total study area. The urban fringe area of Guangzhou and Foshan metropolitan areas covers an area of $2031 \mathrm{~km}^{2}$, and it occupies over $31 \%$ of the total study area. The rural area of Guangzhou and Foshan metropolitan areas covers an area of $3168 \mathrm{~km}^{2}$, and it occupies over $57 \%$ of the total study area.

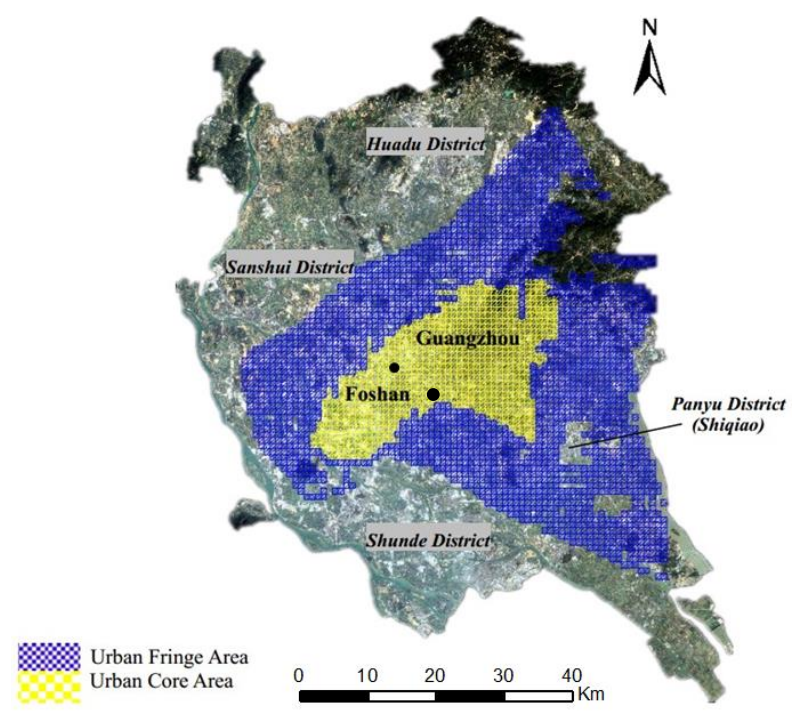

Figure 6. Final delineation of the urban fringe area. 
It is also apparent that the urban area of Guangzhou and Foshan has expanded and become integrated across the municipal administrative boundary. This large-scale metropolitan area has become the core of the Pearl River Delta urban system [24].

\section{Discussion}

In this paper, a novel method based on land cover information for delineating the urban fringe area is demonstrated. The proposed method attempts to better reflect the land use characteristics of the urban fringe area. It aims to minimize human subjectivity and reflect the geographical characteristic of the urban fringe by identifying the optimal scale. Nevertheless, challenges remain and several aspects can be considered for further refinement of the delineation result, which are discussed below.

\subsection{Accuracy Evaluation}

Accuracy assessment remains a challenge without consensus of a measurable definition of the urban fringe. Industrial structure data could be a proxy for indicating the general feature of land cover in a specific region. This study attempts to indirectly evaluate the accuracy by comparing the result with industrial structure data from the "Guangzhou Yearbook 2014" and "Foshan Yearbook 2014", which summarize the Gross Domestic Product (GDP) from primary, secondary and tertiary sectors. As the data are only available at the administrative district level, therefore, the data of Yuexiu, Liwan, Haizhu, Tianhe and Chancheng Districts are calculated as the urban core area, data of Luogang, Huangpu, Baiyun, Panyu, Nansha and Nanhai Districts are calculated as the urban fringe area, and data of Huadu, Sanshui and Shunde Districts are calculated as the rural area, as in Figure 7a. The average industry structure of each area in 2013 is summarized in Figure 7b. Primary industry occurs (e.g., agriculture) more in rural area, secondary industry occurs more in the urban fringe and rural area, and tertiary industry occurs mostly in the urban core area. This result agrees with the general relationship between land cover pattern and economic sector distribution in China. Therefore, it indicates a satisfactory correspondence with the delineation result of the urban fringe. Nevertheless, difficulty pertaining to the assessment of the result remains without a clear definition of the urban fringe.

\subsection{Land Cover Mapping Limitation}

Defining a land cover type based on spectral homogeneity is often difficult in the urban fringe area, as certain land cover types may be spectrally similar to others. Newly developed urban areas may appear similar to fallow farmland on a remote sensing image [25]. Farmland would sometimes be confused with forest or grassland in different growing seasons [1]. In this study, various classification techniques that may influence the mapping result have not been thoroughly tested. Apart from confusion caused by optical signatures, urban development is spatially heterogeneous in different regions, and image quality may vary scene by scene [26]. On the other hand, better accuracy could be achieved if multi-sensor remote sensing data $[27,28]$ and detailed census and socio-economic survey data can be taken into account. In addition, the satellite-derived Land Surface Temperature (LST) will enable a better understanding of the surface conditions across different urban landscapes [29].

\subsection{Applicability}

While the adaptability to urban areas of different sizes is one of the advantages of this method, it should be pointed out that its efficacy suffers from the variation of urban morphology. This method is mostly applicable to the nucleated settlement pattern urban area, while less applicable to the dispersed settlement pattern and linear settlement pattern.

As a landscape phenomenon, the fringe varies from city to city and from one time to another [30]. There is not a universal scale (cell size) that is suitable for all purposes. If this method is to be employed in other smaller or larger sized areas, a new calculation scale should be selected. 


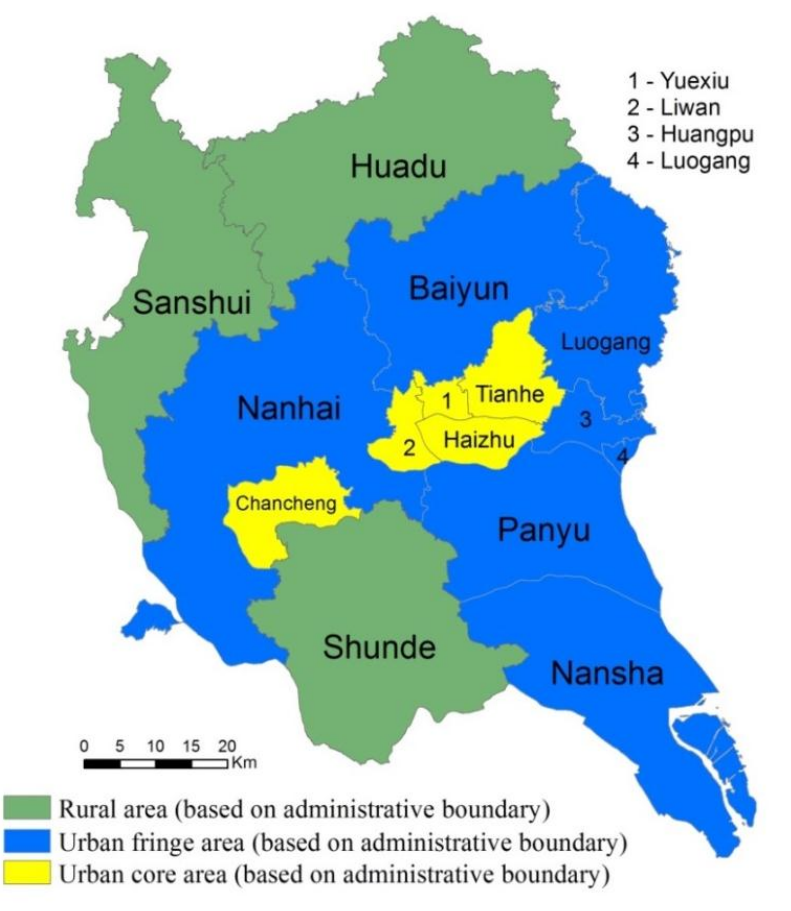

(a)

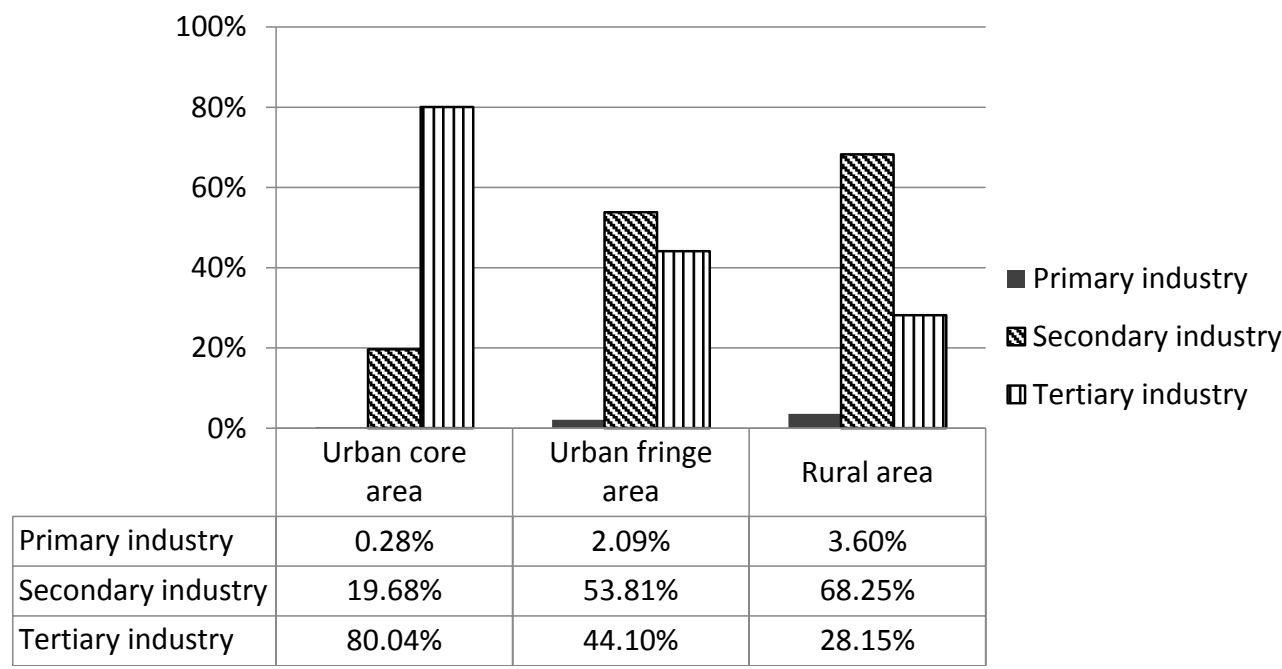

(b)

Figure 7. Industry structure comparison. (a) Division of urban core, urban fringe and rural area based on administrative boundary; (b) Industry structure data of different areas.

\section{Conclusions}

The urban fringe area is the frontier of the urbanization process, characterized as a dynamic and complex system. It also serves as a buffer zone to maintain the ecological balance during urbanization, yet the definition for locating itself in an urban system remains ambiguous. Population density, which is usually utilized as the geographic indicator of the rural and urban level, has been explicitly indicated to be unreliable, as it is organized within certain administrative boundaries [11]. Land cover change information, regarded as a good indicator representing the impact of human activities on earth's environment, offers indirect but objective ways to locate the urban fringe area [31].

This paper, therefore, has reported an updated, systematic, and replicable framework to quantitatively delineate the urban fringe area by a remote sensing, GIS and quantitative method. 
The findings show that information entropy (also known as SHDI) is appropriate as a primary indicator for this task. Optimal scale selection and the integration of various mapping techniques are demonstrated to minimize the subjectivity and increase accuracy. The proposed method appears to be justifiable and reliable according to the evaluation result.

To delineate the area accurately where urban expansion interfaces with sensitive natural ecosystems would help land managers identify areas of concern, offering insight for promoting sustainable development in the urban fringe area. Despite certain limitations, this method provides a new perspective and tool for urban fringe management and planning.

Acknowledgments: This study was supported by the Natural Science Foundation of the China (NSFC) General Research Grant (41471340 and 41171446), Research Grants Council (RGC) of Hong Kong General Research Fund (GRF) (Project No. 203913), and Hong Kong Baptist University Faculty Research Grant (FRG1/14-15/073). We are grateful to the editor and all reviewers for their constructive suggestions and comments that have helped significantly improve the quality of the manuscript.

Author Contributions: Junyi Huang is the corresponding author who theoretically proposed and improved the method and drafted the whole paper; Qiming Zhou contributed greatly to improving the experiment and the manuscript; Zhifeng $\mathrm{Wu}$ initiated the scientific question and provided suggestions to improve the theoretical framework.

Conflicts of Interest: The authors declare no conflict of interest.

\section{References}

1. Yang, Y.; Zhou, Q.; Gong, J.; Wang, Y. An integrated spatio-temporal classification method for urban fringe change detection analysis. Int. J. Remote Sens. 2012, 33, 2516-2531. [CrossRef]

2. Li, X.; Yeh, A.G.O. Analyzing spatial restructuring of land use patterns in a fast growing region using remote sensing and GIS. Landsc. Urban Plan. 2004, 69, 335-354. [CrossRef]

3. Schneider, A.; Friedl, M.A.; Potere, D. Mapping global urban areas using MODIS 500-m data: New methods and datasets based on "urban ecoregions". Remote Sens. Environ. 2010, 114, 1733-1746. [CrossRef]

4. Jindrich, J. When the urban fringe is not suburban. Geogr. Rev. 2010, 100, 35-55. [CrossRef]

5. Louis, H. Die geographische Gliederung von Gross-Berlin (The geographical structure of Greater Berlin). In Landerkundliche Forschung: Krebs-Festschrift; Louis, H., Panzer, W., Eds.; Engelhorn: Stuttgart, Germany, 1936; pp. 146-171. (In German)

6. Desai, A.; Gupta, S.S. Problem of Changing Land Use Pattern in the Rural-Urban Fringe; Concept Publishing Company: New Delhi, India, 1987.

7. Friedberger, M. The rural-urban fringe in the late Twentieth Century. Agric. Hist. 2000, 74, 502-514.

8. Hall, A.S.; Kaufman, S.J.; Ricketts, C.T. Defining urban and rural areas in U.S. epidemiologic studies. J. Urban Health 2006, 8, 162-175. [CrossRef] [PubMed]

9. Lesage, P.J.; Charles, S.J. Using home buyers' revealed preferences to define the urban-rural fringe. J. Geogr. Syst. 2008, 10, 1-21. [CrossRef]

10. Russwurm, L. Urban fringe and urban shadow. In Urban Fringe and Urban Shadow; Holt, Rinehart and Winston: Toronto, ON, Canada, 1975; pp. 148-164.

11. Weeks, J.R. Defining urban areas. In Remote Sensing of Urban and Suburban Areas; Rashed, T., Jürgens, C., Eds.; Springer-Verlag, Inc.: New York, NY, USA, 2010; pp. 33-45.

12. Banzhaf, E.; Grescho, V.; Kindler, A. Monitoring urban to peri-urban development with integrated remote sensing and GIS information: A Leipzig, Germany case study. Int. J. Remote Sens. 2009, 30, 1675-1696. [CrossRef]

13. Yang, X.; Fu, B.; Chen, L. Remote sensing and geospatial analysis for landscape pattern characterization. In Landscape Ecology for Sustainable Environment and Culture; Fu, B., Jones, B., Eds.; Springer: Dordrecht, The Netherlands, 2013; pp. 205-221.

14. Zhang, W.; Fang, X.; Zhang, L. Method to identify the urban-rural fringe by TM images. J. Remote Sens. 1999, 3, 199-202. (In Chinese)

15. Wilson, E.H.; Hurd, J.D.; Civco, D.L.; Prisloe, M.P.; Arnold, C. Development of a geospatial model to quantify describe and map urban growth. Remote Sens. Environ. 2004, 86, 275-285. [CrossRef] 
16. Angel, S.; Parent, J.; Civco, D. Urban sprawl metrics: An analysis of global urban expansion using GIS. In Proceedings of the ASPRS 2007 Annual Conference, Tampa, FL, USA, 7-11 May 2007; p. 12.

17. Peterson, D.L.; Parker, T.V. Ecological Scale Theory and Applications; Columbia University Press: New York, NY, USA, 1998.

18. Quattrochi, D.A.; Goodchild, M.F. Scale in Remote Sensing and GIS; CRC Press: New York, NY, USA, 1997.

19. Corry, R.C.; Nassauer, J.I. Limitations of using landscape pattern indices to evaluate the ecological consequences of alternative plans and designs. Landsc. Urban Plan. 2005, 72, 265-280. [CrossRef]

20. Wu, J. Key concepts and research topics in landscape ecology revisited: 30 years after the Allerton Park workshop. Landsc. Ecol. 2013, 28, 1-11. [CrossRef]

21. Senft, A.R. Species Diversity Patterns at Ecotones; University of North Carolina: Chapel Hill, NC, USA, 2009.

22. Graves, R. Ecotone. Available online: http://www.eoearth.org/view/article/152345 (accessed on 15 February 2016).

23. Ludwig, J.A.; Reynolds, J.F. Statistical Ecology; John Wiley \& Sons, Inc.: New York, NY, USA, 1988.

24. Bhatta, B. Analysis of urban growth pattern using remote sensing and GIS: A case study of Kolkata, India. Int. J. Remote Sens. 2009, 30, 4733-4746. [CrossRef]

25. Schneider, A. Monitoring land cover change in urban and peri-urban areas using dense time stacks of Landsat satellite data and a data mining approach. Remote Sens. Environ. 2012, 124, 689-704. [CrossRef]

26. Gong, P.; Yu, L.; Li, C.; Wang, J.; Liang, L.; Li, X.; Ji, L.; Bai, Y.; Cheng, Y.; Zhu, Z. A new research paradigm for global land cover mapping. Ann. GIS 2016, 22, 1-16. [CrossRef]

27. Brook, A.; Ben-Dor, E.; Richter, R. Modelling and monitoring urban built environment via multi-source integrated and fused remote sensing data. Int. J. Image Data Fusion 2013, 4, 2-32. [CrossRef]

28. Dahiya, S.; Garg, P.K.; Jat, M.K. A comparative study of various pixel-based image fusion techniques as applied to an urban environment. Int. J. Image Data Fusion 2013, 4, 197-213. [CrossRef]

29. Guo, G.; Wu, Z.; Xiao, R.; Chen, Y.; Liu, X.; Zhang, X. Impacts of urban biophysical composition on land surface temperature in urban heat island clusters. Landsc. Urban Plan. 2015, 135, 1-10. [CrossRef]

30. Pryor, R.J. Defining the rural-urban fringe. Soc. Forces 1968, 47, 202-215. [CrossRef]

31. Zhou, Q.; Sun, B. Analysis of spatio-temporal pattern and driving force of land cover change using multi-temporal remote sensing images. Sci. China Technol. Sci. 2010, 53, 111-119. [CrossRef]

(C) 2016 by the authors; licensee MDPI, Basel, Switzerland. This article is an open access article distributed under the terms and conditions of the Creative Commons Attribution (CC-BY) license (http://creativecommons.org/licenses/by/4.0/). 